This item was submitted to Loughborough's Research Repository by the author.

Items in Figshare are protected by copyright, with all rights reserved, unless otherwise indicated.

\title{
Body mapping of thermoregulatory and perceptual responses of males and females running in the cold
}

PLEASE CITE THE PUBLISHED VERSION

http://dx.doi.org/10.1016/j.jtherbio.2013.04.005

PUBLISHER

(C) Elsevier

VERSION

AM (Accepted Manuscript)

LICENCE

CC BY-NC-ND 4.0

\section{REPOSITORY RECORD}

Fournet, Damien, Lindsey Ross, Thomas Voelcker, Bernard Redortier, and George Havenith. 2019. "Body Mapping of Thermoregulatory and Perceptual Responses of Males and Females Running in the Cold". figshare. https://hdl.handle.net/2134/12486. 
This item was submitted to Loughborough's Institutional Repository (https://dspace.lboro.ac.uk/) by the author and is made available under the following Creative Commons Licence conditions.

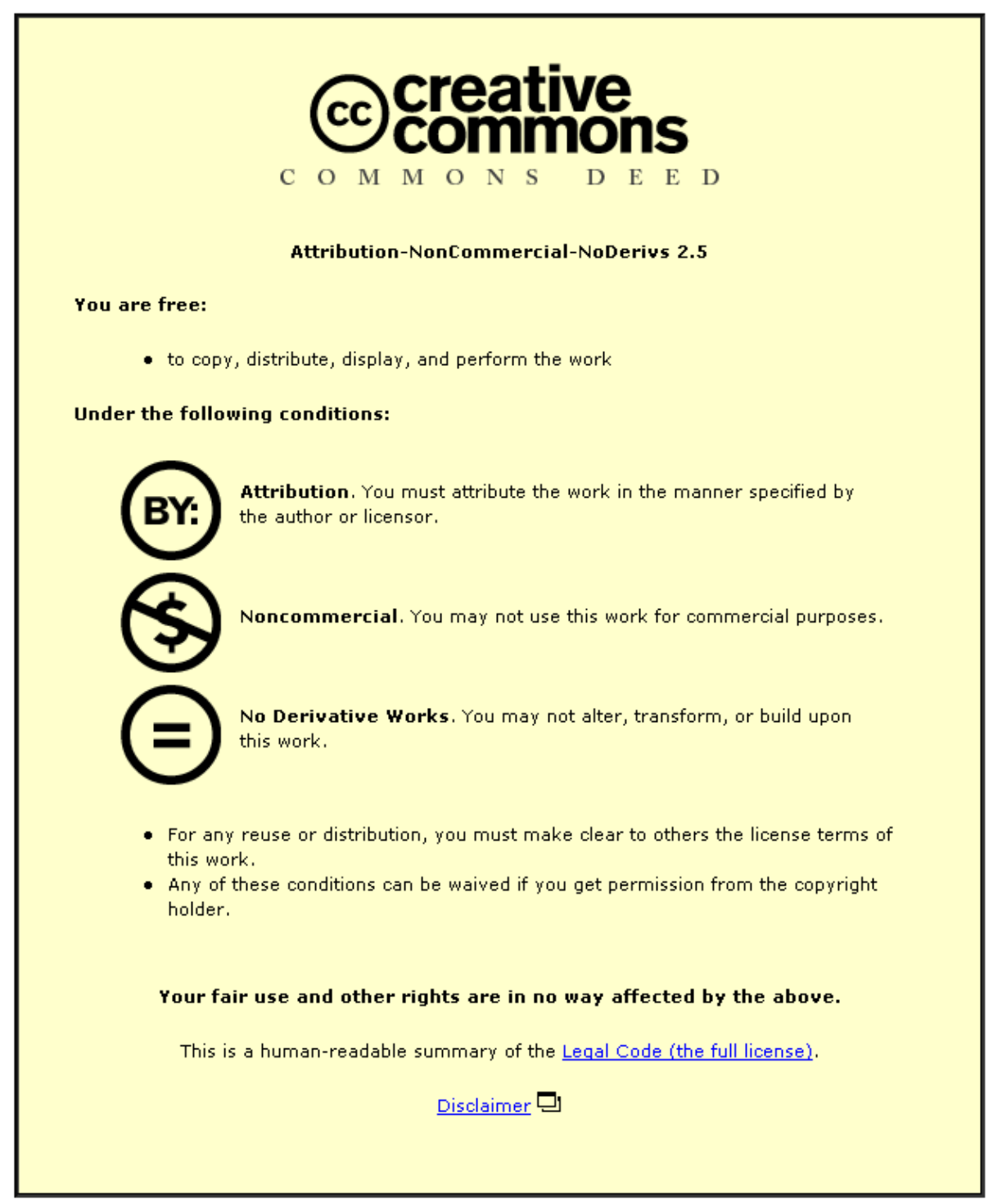

For the full text of this licence, please go to: http://creativecommons.org/licenses/by-nc-nd/2.5/ 


\section{Elsevier Editorial System(tm) for Journal of Thermal Biology}

Manuscript Draft

Manuscript Number: TB-D-12-00129R3

Title: Body mapping of thermoregulatory and perceptual responses of males and females running in the cold

Article Type: Full Length Article

Keywords: skin temperature; skinfold thickness; exercise; sex; infrared thermography

Corresponding Author: Prof George Havenith, PhD

Corresponding Author's Institution: Loughborough University

First Author: Damien Fournet

Order of Authors: Damien Fournet; Lindsey Ross; Thomas Voelcker; Bernard Redortier; George

Havenith

Abstract: Thermoregulatory parameters during exercise are typically reported as global responses (Tcore and mean Tsk). In contrast, this study investigated regional skin temperatures (Tsk) over the body, in relation to regional skinfold thickness and regional perceptual responses for both sexes using a body-mapping approach. Nine males and nine females, of equivalent fitness, minimally clothed, ran for 40 minutes at $70 \% \mathrm{VO} 2 \mathrm{max}$ in a $10^{\circ} \mathrm{C}, 50 \% \mathrm{rh}, 2.8 \mathrm{~m} . \mathrm{s}-1$ air velocity environment. Tsk was recorded by infrared thermography and processed to obtain population-averaged body maps. Rectal temperature and heart rate were monitored continuously throughout the running trial. Skinfold thickness was obtained for 24 sites and thermal sensation votes for 11 body regions.

Males and females had similar rectal temperature, heart rate and regional sensations. Whole-body maps of Tsk highlighted the significantly lower regional Tsk for females $\left(-1.6^{\circ} \mathrm{C}\right.$ overall, $\left.\mathrm{p}<0.01\right)$. However, the distribution of Tsk across the body was similar between sexes and this was not correlated with the distribution of skinfold thickness, except for the anterior torso. On the other hand, regional thermal sensation votes across the body were correlated with Tsk distribution during exercise (females: $r=0.61$, males $r=0.73, p<0.05$ ), but not at rest. Our thermographic results demonstrate the similar Tsk distribution for active males and females during submaximal running in the cold, though shifted to a lower mean value for females. This Tsk distribution was associated with regional sensations but not with local fat thickness. The described body-mapping approach can have implications in physiological modelling and clothing design 


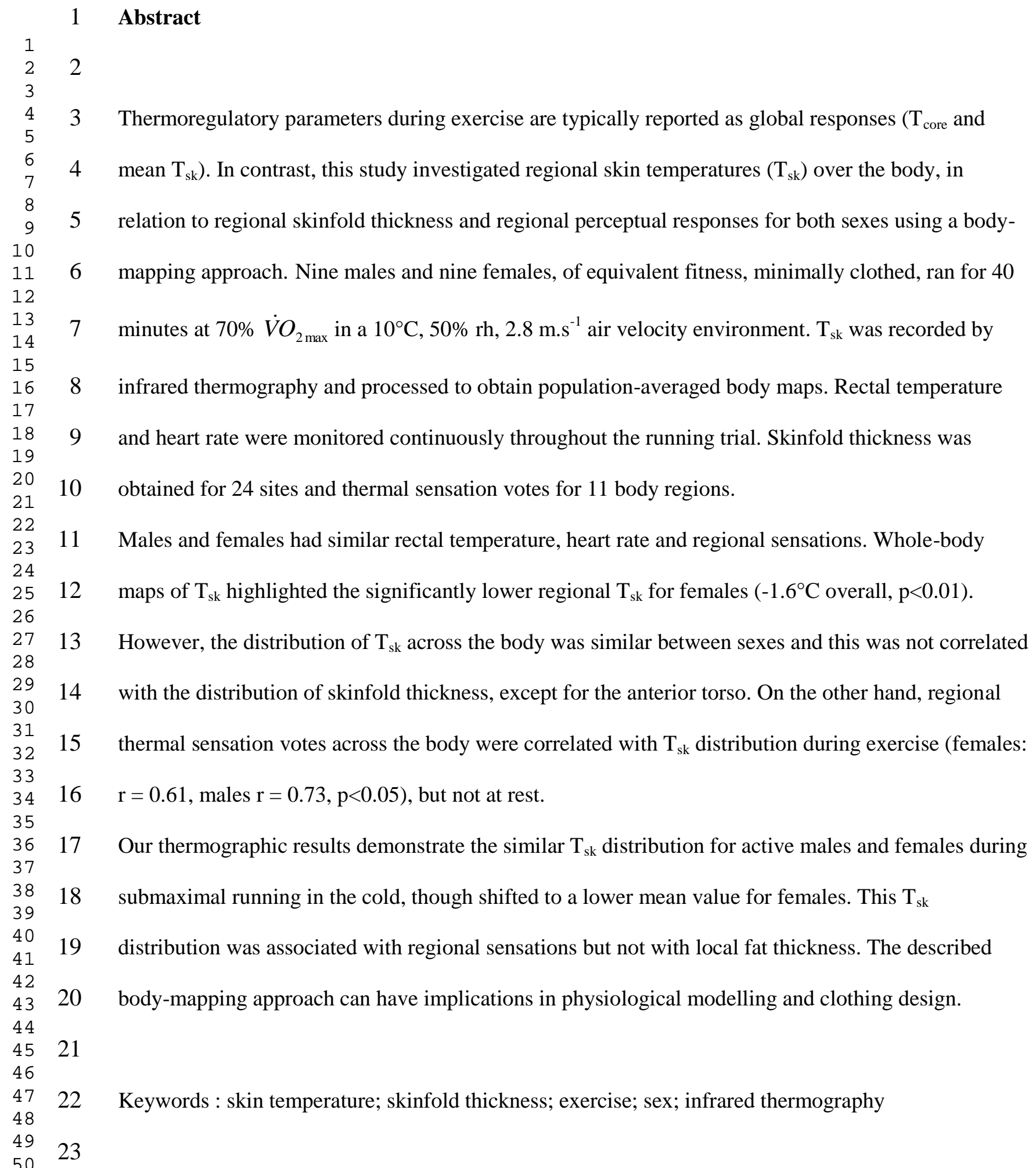

3 Thermoregulatory parameters during exercise are typically reported as global responses $\left(\mathrm{T}_{\text {core }}\right.$ and

4 mean $\left.\mathrm{T}_{\mathrm{sk}}\right)$. In contrast, this study investigated regional skin temperatures $\left(\mathrm{T}_{\mathrm{sk}}\right)$ over the body, in

5 relation to regional skinfold thickness and regional perceptual responses for both sexes using a body-

6 mapping approach. Nine males and nine females, of equivalent fitness, minimally clothed, ran for 40

7 minutes at $70 \% \dot{V} O_{2 \max }$ in a $10^{\circ} \mathrm{C}, 50 \% \mathrm{rh}, 2.8 \mathrm{~m} \cdot \mathrm{s}^{-1}$ air velocity environment. $\mathrm{T}_{\text {sk }}$ was recorded by

8 infrared thermography and processed to obtain population-averaged body maps. Rectal temperature

9 and heart rate were monitored continuously throughout the running trial. Skinfold thickness was

10 obtained for 24 sites and thermal sensation votes for 11 body regions.

11 Males and females had similar rectal temperature, heart rate and regional sensations. Whole-body

12 maps of $\mathrm{T}_{\mathrm{sk}}$ highlighted the significantly lower regional $\mathrm{T}_{\mathrm{sk}}$ for females $\left(-1.6^{\circ} \mathrm{C}\right.$ overall, $\left.\mathrm{p}<0.01\right)$.

13 However, the distribution of $\mathrm{T}_{\text {sk }}$ across the body was similar between sexes and this was not correlated

14 with the distribution of skinfold thickness, except for the anterior torso. On the other hand, regional

15 thermal sensation votes across the body were correlated with $\mathrm{T}_{\mathrm{sk}}$ distribution during exercise (females:

$16 r=0.61$, males $r=0.73, p<0.05)$, but not at rest.

17 Our thermographic results demonstrate the similar $\mathrm{T}_{\mathrm{sk}}$ distribution for active males and females during

18 submaximal running in the cold, though shifted to a lower mean value for females. This $\mathrm{T}_{\mathrm{sk}}$

19 distribution was associated with regional sensations but not with local fat thickness. The described

20 body-mapping approach can have implications in physiological modelling and clothing design.

22 Keywords : skin temperature; skinfold thickness; exercise; sex; infrared thermography 


\section{Introduction}

2 Temperature regulation is dependent upon ascending sensory information from deep and skin

3 thermoreceptors widely distributed in the body (Werner and Reents, 1980). Core and mean skin

4 temperature $\left(\overline{T_{s k}}\right)$ are often considered as the regulatory parameters. Body-mapping, i.e the study of

5 thermoregulatory responses for different body regions, has gained attention over recent years after

6 earlier works mainly focussed on global responses. Recent data from studies about sweat mapping

7 (Havenith et al., 2008; Smith and Havenith, 2012) and thermal sensitivity distribution (Ouzzahra et al.,

8 2012) are now used in models of thermoregulation (Fiala et al., 2012) as well as in the design of

9 thermal manikins and clothing (Havenith et al., 2008). Little is known about the spatial distribution of body temperatures, especially skin temperature $\left(\mathrm{T}_{\mathrm{sk}}\right)$. The topography of $\mathrm{T}_{\mathrm{sk}}$ distribution across the body can have some thermoregulatory and perceptual significance (Candas, 2005). It is even more relevant in cold environments where $\mathrm{T}_{\mathrm{sk}}$ differences between regions are larger (Werner and Reents, 1980).

In the literature, $\mathrm{T}_{\mathrm{sk}}$ responses are reported via the dynamics of $\overline{T_{s k}}$ usually computed from several contact point measurements from up to 15 body regions (Choi et al., 2007). However, large point-topoint $T_{\text {sk }}$ variations have been highlighted in relatively small areas of the body (Frim et al., 1990) and this questions the representativeness of such contact measurements.

Infrared thermography offers an alternative non-contact method in the evaluation of $\mathrm{T}_{\mathrm{sk}}$ with the potential of mapping $\mathrm{T}_{\mathrm{sk}}$ distribution over the whole-body. Several studies have used this method during exercise and specifically whilst running (Clark et al., 1977; Merla et al., 2010). However, no studies have attempted to combine the individual infrared images (thermograms) in order to give a population-averaged pattern of $\mathrm{T}_{\mathrm{sk}}$ distribution. Moreover, patterns of male versus female $\mathrm{T}_{\mathrm{sk}}$ distribution have only been described qualitatively for two participants at rest in a $22^{\circ} \mathrm{C}$ environment (Clark and Edholm, 1985).

Sex-differences in thermoregulatory responses, have mainly been reported as overall responses.

During exercise in the cold, $\overline{T_{s k}}$ is $1-2^{\circ} \mathrm{C}$ lower for females (Graham, 1988) and only one study, using contact sensors, actually compared regional $\mathrm{T}_{\text {sk }}$ between sexes (Walsh and Graham, 1986). Differences 
1 in $\mathrm{T}_{\mathrm{sk}}$ between sexes have sometimes been attributed to differences in subcutaneous fat (Wagner and

2 Horvath, 1985), acting as a passive layer of insulation impeding heat transfer from the core to the skin.

3 In the cold, peripheral cutaneous vasoconstriction maximises its insulatory benefits. The distribution

4 of subcutaneous fat thickness over the body, also called fat patterning, is different in males and

5 females (Mueller and Joos, 1985). Together with hormonal differences, this corresponds to a true

6 sexual dimorphism that can lead to sex-differences in thermoregulation. These different distribution

7 patterns can locally alter heat transfers, and it is suggested that $\mathrm{T}_{\mathrm{sk}}$ distribution reflects the regional

8 subcutaneous fat distribution (LeBlanc, 1954), though this has never been verified.

9 Lastly, the role of $\mathrm{T}_{\mathrm{sk}}$ in the generation of thermal sensations is well recognized (Candas, 2005) with

10 thermoreceptors responding to static temperature and rates of change of temperature (Hensel, 1973).

11 Although this determinism has been explored for individual regions at rest (Zhang et al., 2010) and

12 overall response during exercise (Gagge et al., 1969), no reports have looked at the relationships

13 between thermal sensations across the body and $\mathrm{T}_{\mathrm{sk}}$ distribution.

14 A body-mapping approach was therefore used in the present study in order to investigate different

15 thermoregulatory and perceptual variables. In the context of running in the cold, it was hypothesized

16 that males and females would have different thermographic body maps of $\mathrm{T}_{\mathrm{sk}}$ due to their differences

17 in fat patterning. Moreover, the expected lower $\mathrm{T}_{\mathrm{sk}}$ for females may lead to sex-differences in regional

18 thermal sensation responses.

\section{Methods}

21 Nine males and nine females (aged 18-25), all physically active Caucasians, participated in the 22 experiment. All experimental procedures were approved by the Loughborough University Ethical 23 Committee and were fully explained to the participants before obtaining informed written consent and 24 completing a health screen questionnaire.

25 Height and body mass were obtained as well as skinfold measurements using a Harpenden caliper at 2624 locations across the right side of the body (Table 1). The latter provided a detailed body map of 27 skinfold thickness. Skinfolds were also used to calculate body fat percentage (\%BF) (Hayward and 
1 Wagner, 2004). Maximal oxygen uptake ( $\left.\dot{V} O_{2 \max }\right)$ was predicted from a sub-maximal test (Whaley et

2 al., 2009) on a treadmill (h/p cosmos mercury 4.0, Nussdorf-Traunstein, Germany). Exercise intensity

3 for the experimental session was set at $70 \% \dot{V} O_{2 \max }$ which was chosen to reflect a common training

4 speed of regular active runners.

5 Males were provided with swimming trunks and females low-cut running shorts and bras (Decathlon,

6 Villeneuve d'Ascq, France). Rectal temperature $\left(\mathrm{T}_{\mathrm{re}}\right)$ was monitored continuously using a thermistor

7 (Grant Instruments, Cambridge, UK) inserted $10 \mathrm{~cm}$ beyond the anal sphincter. Heart rate (HR) was

8 recorded using a Polar RS600 monitor (Polar Electro Oy, Kempele, Finland).

9 The trial was designed to reproduce a typical outdoor running scenario with a selection of four

10 different stages for specific measurements. Following a 10-min period of stabilisation at rest in the

$1122^{\circ} \mathrm{C}$ preparation room, participants entered the $10^{\circ} \mathrm{C}$ climatic chamber, stood at rest for 5 minutes on

12 the treadmill (PRE), ran for 10 minutes (T10) and ran for another 30 minutes to complete the 40-min

13 exercise bout (T40). Exercise was followed by a 10-min recovery period standing on the treadmill

14 (POST). All experiments were conducted in the controlled climatic chamber in a $9.9 \pm 0.5^{\circ} \mathrm{C}$

15 environment and $54 \pm 6 \%$ relative humidity. This type of conditions was chosen to induce large $\mathrm{T}_{\text {sk }}$

16 variations and were in line with others (Werner and Reents, 1980; Gagge et al., 1969). During

17 exercise, a $2.8 \pm 0.3 \mathrm{~m} . \mathrm{s}^{-1}$ frontal air speed was present. Body sweat loss was calculated from body

18 mass loss adjusted for water intake and corrected for metabolic and respiratory mass losses. Within the

19 group of females, 5 were tested during the follicular phase and 4 during the luteal phase of the

20 menstrual cycle.

21 Perceptual responses were obtained at the end of each stage with the rate of perceived exertion (RPE)

22 using the 6-20 Borg scale (Borg, 1970) and the overall and regional thermal sensations using an

23 extended Gagge 21-point bipolar scale (from extremely cold to extremely hot) (Gagge et al., 1969).

24 Eleven regions were investigated, extending the list of Pellerin et al. (2004) and for the limbs

25 separating anterior and posterior to account for effects of the front wind applied: chest, abdomen,

26 upper and lower back, anterior and posterior arms, anterior and posterior hands, anterior and posterior

27 legs, face. 
1 Whole-body $\mathrm{T}_{\mathrm{sk}}$ was then recorded with the participant standing in an anatomical position using an

2 infrared camera (Thermacam B2, FLIR Systems Ltd, West Malling, Kent, UK, spectral range 7.5 to $313 \mu \mathrm{m}$, accuracy $\pm 2^{\circ} \mathrm{C}$, thermal sensitivity $\pm 0.1^{\circ} \mathrm{C}$,). A series of five different thermograms (anterior

4 upper body, posterior upper body, anterior lower body, posterior lower body and right side) were taken 5 immediately at the end of each stage (PRE, T10, T40, POST). The HR belt was worn for 5 minutes 6 and removed 5 minutes before each infrared measurement to reduce its influence on heat exchanges at 7 the skin. A reference surface temperature (measured by a thermistor at $\pm 0.1^{\circ} \mathrm{C}$ ) was included in all 8 images for post-calibration of absolute temperature in order to improve the device absolute accuracy.

9 Females removed their bras so that the bare chest could be measured.

10 Temperature correction was performed on individual infrared images using FLIR ThermaCam 11 Researcher Pro 2.8 to account for various parameters, i.e ambient temperature, reflected temperature, relative humidity, distance (1.9m) and emissivity (0.98) (Steketee, 1973). Image processing was then performed using a custom-made tool under MATLAB R2009a (The MathWorks Inc., Natick, USA) to account for between-subject differences in body size and shape. Following image registration (selection of control points), all thermograms were morphed, i.e. projected, onto a reference body shape chosen as a male and female with median anthropometric characteristics. Morphed individual thermograms were then averaged to obtain population-averaged absolute body maps of $\mathrm{T}_{\text {sk }}$. Lastly, relative or normalised $\mathrm{T}_{\mathrm{sk}}$ body maps were computed by dividing the absolute maps by the group $\overline{T_{s k}}$ at each specific stage, calculated as the arithmetic average of all skin surface pixels except for groin, feet and scalp. Image processing was performed manually based on anatomical landmarks in order to avoid the selection of artefacts pixels caused by the edge effect of the curved human body.

The morphing procedure induced pixel distorsion around the body contour depending on body geometry of each individual in relation to the reference body shape. The transformation led to a $\pm 15 \%$ difference (expansion or constriction) in effectve body pixel count from morphed vs original thermogram, though this only affected the topographical representations of the $\mathrm{T}_{\mathrm{sk}}$ patterns (body maps). On the other hand, for quantitative analysis, $\mathrm{T}_{\mathrm{sk}}$ data were obtained before morphing based on a segmentation in close association with superficial musculature. $\mathrm{T}_{\mathrm{sk}}$ values for palmar and dorsal hands 
1 were included but the hands are not reported in the body map representations due to limited resolution

2 in these areas.

3 A two-way repeated measures ANOVA (SPSS Inc, Chicago, IL, USA) was used to investigate the 4 main effect of TIME of exposure, and SEX on the different dependent variables: $\overline{T_{s k}}$, regional $T_{\mathrm{sk}}, T_{\mathrm{re}}$,

5 HR. Holm-Bonferroni corrections was applied to allow for multiple comparisons when different body

6 sites were compared. Pearson correlation coefficients were obtained following regression analysis

7 between regional $\mathrm{T}_{\mathrm{sk}}$ and regional skinfold thickness on one hand, and regional thermal sensation and

8 regional $\mathrm{T}_{\mathrm{sk}}$ on the other.

\section{Results}

11 The following participants characteristics were obtained for females vs males ( $171 \pm 3 \mathrm{~cm}$ vs $182 \pm 4$ $\mathrm{cm}, 66.6 \pm 5.0 \mathrm{~kg}$ vs $79.5 \pm 4.3 \mathrm{~kg}, \mathrm{p}<0.01)$. Females had significantly greater body fat percentage compared to males $(21.6 \pm 2.8 \%$ vs $9.5 \pm 2.4 \%, \mathrm{p}<0.01)$. Both groups had similar maximal fitness level (females vs males: $50.3 \pm 5.3 \mathrm{ml} \cdot \mathrm{min}^{-1} \cdot \mathrm{kg}^{-1}$ vs $53.7 \pm 4.1 \mathrm{ml} \cdot \mathrm{min}^{-1} \cdot \mathrm{kg}^{-1}$, NS) and they exercised at a similar running speed $\left(9.5 \pm 1.1 \mathrm{~km} \cdot \mathrm{h}^{-1}\right.$ vs $10.2 \pm 0.9 \mathrm{~km} \cdot \mathrm{h}^{-1}$, NS) during the experimental trial.

Overall thermoregulatory responses highlighted a significant sex-difference for whole-body $\overline{T_{s k}}$ but no difference in terms of $\mathrm{T}_{\mathrm{re}}$, body sweat loss and HR between males and females. Whole-body $\overline{T_{s k}}$ was indeed $1.6^{\circ} \mathrm{C}$ significantly lower for females (females vs males: $26.9 \pm 0.8^{\circ} \mathrm{C}$ vs $28.9 \pm 0.9^{\circ} \mathrm{C}, \mathrm{p}<0.01$ at PRE; $22.4 \pm 0.9^{\circ} \mathrm{C}$ vs $24.0 \pm 0.9^{\circ} \mathrm{C}, \mathrm{p}<0.01$ at $\mathrm{T} 10 ; 21.9 \pm 1.1^{\circ} \mathrm{C}$ vs $23.5 \pm 1.5^{\circ} \mathrm{C}, \mathrm{p}<0.05$ at $\mathrm{T} 40$; $24.5 \pm 1.2^{\circ} \mathrm{C}$ vs $25.7 \pm 0.8^{\circ} \mathrm{C}, \mathrm{p}<0.05$ at POST). Dynamics of $\overline{T_{s k}}$ was however the same between the two groups with no TIME*SEX interaction effect.

There were no sex-differences in the dynamics of $\mathrm{T}_{\mathrm{re}}$ and their absolute values throughout the wholeprotocol including the four specific stages (females vs males: $37.5 \pm 0.3^{\circ} \mathrm{C}$ vs $37.7 \pm 0.2^{\circ} \mathrm{C}$ at $\mathrm{PRE}$, $38.1 \pm 0.2^{\circ} \mathrm{C}$ vs $38.1 \pm 0.2^{\circ} \mathrm{C}$ at $\mathrm{T} 10 ; 38.5 \pm 0.3^{\circ} \mathrm{C}$ vs $38.5 \pm 0.2^{\circ} \mathrm{C}$ at $\mathrm{T} 40 ; 37.9 \pm 0.4^{\circ} \mathrm{C}$ vs $38.1 \pm 0.2^{\circ} \mathrm{C}$ at POST, all NS). Moreover, there was no sex-difference in body sweat loss (females $185 \pm 133 \mathrm{~g}$, males $212 \pm 39 \mathrm{~g}, \mathrm{NS}$ ) and no differences in HR and its dynamics with a similar plateau at $150 \pm 13 \mathrm{bpm}$ for females $152 \pm 9 \mathrm{bpm}$ for males. 
1 Overall perceptual responses were similar between females and males considering RPE (females vs

2 males: $11 \pm 1$ vs $11 \pm 2$ at $\mathrm{T} 10,13 \pm 2$ vs $13 \pm 2$ at $\mathrm{T} 40$, NS) as well as whole-body thermal sensation

3 ranging on average from cool at PRE to neutral / slightly cool at T40, with a large inter-individual

4 variability in both groups.

5 The body-mapping approach applied to the evaluation of skinfold thickness is presented in Table 1. A

6 majority of skinfolds sites had a significantly larger thickness for females compared to males. The

7 largest difference was observed at the triceps, thigh and lumbosacral regions with a respectively

$8+121 \%,+88 \%,+68 \%$ larger skinfold thickness for females.

9 Females exhibited lower regional $\mathrm{T}_{\mathrm{sk}}$ at all stages and most of the significant sex-differences in

10 absolute $\mathrm{T}_{\mathrm{sk}}$ were observed in the anterior and posterior legs, the upper and lower back as observed in 11 the population-averaged body maps of absolute $\mathrm{T}_{\text {sk }}$ (Figure 1). There was no TIME*SEX interaction

stages. The evolution of regional skin temperatures followed $\overline{T_{s k}}$ dynamics over the four stages. The anterior skin temperatures dropped more during the running than the posterior for both sexes (on average $-7^{\circ} \mathrm{C}$ vs $\left.-5^{\circ} \mathrm{C}\right)$.

Relative $\mathrm{T}_{\mathrm{sk}}$ distribution was similar between females and males which represents the main finding of the present study (Figure 1) and this was consistent throughout the protocol. No significant relationship was found between the whole-body $\mathrm{T}_{\mathrm{sk}}$ distribution and the skinfold thickness distribution across the body (24 sites) for both groups neither at rest nor during exercise (Figure 2A,B). This relationship became significant only when analysed for the variations over the anterior torso separately (8 sites), and solely at T40 (females $\mathrm{r}=-0.71, \mathrm{p}=0.11$; males $\mathrm{r}=-0.85, \mathrm{p}<0.05$ ).

\section{Despite the significantly lower $\mathrm{T}_{\text {sk }}$ for females, there were no sex-differences in regional thermal} sensation in the eleven body regions throughout the protocol. At T40, the extreme regions were the hands, perceived as slightly cool, and the back perceived as above neutral for both groups. There was a significant relationship between the distribution of regional thermal sensations and the distribution of regional $\mathrm{T}_{\text {sk }}$ but only during exercise (Figure $2 \mathrm{C}, \mathrm{D}$ ). 


\section{Discussion}

2 The present study produced for the first time population-averaged whole-body maps of $\mathrm{T}_{\mathrm{sk}}$ distribution

3 for minimally clothed Caucasian males and females during submaximal running in a $10^{\circ} \mathrm{C}$

4 environment. Using a body-mapping approach similar to recent sweat and sensitivity mapping

5 (Havenith et al., 2008; Smith and Havenith, 2012; Ouzzahra et al., 2012), it gives new insights in the

6 spatial resolution of thermoregulatory and perceptual variables with a special emphasis on the

7 influence of skinfold thickness. The main findings of this experiment on a physically active population

8 can be summarised as follows: (1) Females exhibited lower $\overline{T_{s k}}$ and regional $\mathrm{T}_{\mathrm{sk}}$ than males, (2) $\mathrm{T}_{\mathrm{sk}}$

9 distribution pattern was similar between males and females, (3) $\mathrm{T}_{\mathrm{sk}}$ distribution was not associated with the regional variations of skinfold thickness across the body, (4) The regional variation of thermal sensations across the body were positively correlated with $\mathrm{T}_{\mathrm{sk}}$ distribution during exercise, though different per sex. For a certain sensation, females had a lower $\mathrm{T}_{\mathrm{sk}}$.

(1) The present thermographic data support the well documented sex difference in $\overline{T_{s k}}$ based on contact measurements showing an absolute $1-2^{\circ} \mathrm{C}$ colder $\overline{T_{s k}}$ for females at rest and during exercise in the cold (Graham, 1988; Walsh and Graham, 1986). In agreement with others (Walsh and Graham, 1986), $T_{\text {sk }}$ in the limbs and trunk, especially at the back, were colder for females compared to males. (2) Despite the absolute $T_{\text {sk }}$ differences, our population-averaged relative body maps highlighted the similar topography of regional $\mathrm{T}_{\mathrm{sk}}$ distribution between females and males (Figure 1). Specific exercise-related features in the body maps were observed such as the warmer skin overlying active gastrocnemii and hamstrings muscles. Other thermographic studies also documented this feature whilst running but on only one representative participant (Clark et al., 1977; Merla et al., 2010). Interestingly, the $\mathrm{T}_{\mathrm{sk}}$ body maps paralleled the body maps of glucose metabolism obtained after running by $3 \mathrm{D}$ positron emission tomography using ${ }^{18} \mathrm{~F}$-2-fluoro-2-deoxyglucose (Iemitsu et al., 2000), emphasizing the important influence of regional heat production on regional $\mathrm{T}_{\mathrm{sk}}$, overpowering the increased convective heat loss in the swinging lower limbs.

The colder Y-shape area over the abdominal, hypogastric and pectoral regions is in line with observations at rest (Clark and Edholm, 1985) or after running (Clark et al., 1977; Merla et al., 2010) 
1 on individual athletes. Higher breast temperatures for females were caused by the insulation provided

2 by the bra and prevented the definition of a plain Y-shape as observed in males. This could not be

3 avoided as running without a bra was not acceptable at these running speeds. In the posterior torso, the

$4 \quad \mathrm{Y}$-shape region of higher $\mathrm{T}_{\mathrm{sk}}$ was noticeable and similar to that found for an individual male and

5 female at rest (Clark and Edholm, 1985) and close to the T-shape of a single male runner (Clark et al.,

6 1977). The body maps also allowed the identification of a warm "core" (Clark and Edholm, 1985)

7 including the face, sternal and neck regions. Lastly, the distribution of $\mathrm{T}_{\mathrm{sk}}$ in the limbs partly

8 challenges the classical observation of a "cephalo-caudal distribution" (Candas, 2005) of $\mathrm{T}_{\mathrm{sk}}$, i.e colder

9 towards the extremities, which may only apply during prolonged rest.

10 (3) The body-mapping analysis revealed that within each sex, $T_{\mathrm{sk}}$ distribution did not reflect the 11 regional variations of skinfold thickness across the body, as firstly hypothesised. The gynoid (females) vs android (males) fat distribution (Mueller and Joos, 1985) did not impact the spatial variations of $\mathrm{T}_{\text {sk. }}$. Studies classically reporting an effect of fat thickness on $\mathrm{T}_{\mathrm{sk}}$ were focused on inter-individual variations for single body regions (Frim et al., 1990; LeBlanc, 1954). Our body-mapping approach explored the variations between body regions over the body. Despite some regions with thicker fat deposits (e.g thigh) being indeed one of the coldest, there was no topographically consistent determinism over the whole body. Within the anterior torso however, skinfold thickness variations appeared to influence $\mathrm{T}_{\mathrm{sk}}$ distribution for both groups during exercise. It can be hypothesized that insulation of the moderately perfused pectoral and abdominal muscles (Veicsteinas et al., 1982) may also have contributed to the specifc $\mathrm{Y}$-shape region of colder $\mathrm{T}_{\text {sk. }}$

All $\mathrm{T}_{\mathrm{sk}}$ determinants must be taken into account in the description of the thermal patterns. The exposition of the anterior torso to strong convective heat exchange (relative wind) may partly explain the colder $\mathrm{T}_{\mathrm{sk}}$ compared to the posterior torso.

The role of cutaneous perfusion is also highly important in the thermal patterns (Hunold et al., 1992) as it modifies the tissue heat conductance. Vasomotor tone is autonomously controlled and dynamically dictates tissue insulation as opposed to the passive influence of fat thickness which refers to fixed body characteristics. The influence of cutaneous perfusion may also vary from site to site (Park et al., 1997). Following a period of cold and exercise-induced vasoconstriction at the start of the 
1 trial (Johnson, 1992), some reflex active vasodilation and more superficial blood flow may have

2 limited the temperature drop in the posterior torso, especially along the spinal arteries, or in the

3 regions overlying the aortic arch and the routes of the carotid and brachial arteries (Figure 1).

4 Cutaneous blood flow measurements during exercise were deemed impractical so the male and female

5 results cannot be compared to this effect. However, based on literature results, it may be assumed that

6 sex differences in skin blood flow would be limited (Park et al., 1997) and regional differences in

7 blood flow have also been found to be relatively small between the trunk, arms and legs in various

8 environments (Werner and Reents, 1980). Baroreceptor unloading induced by the transition from

9 running to standing may have caused some reductions in regional blood flow (Crandall et al. 1996;

10 Mack et al., 2001) and regional sweat rates (Mack et al., 2001) though the influence of baroreceptor

11 unloading on sweat rate is yet not fully understood. Moreover, the cessation of exercise was also associated with a sudden reduction in evaporative and convective heat loss due to the cessation of the

13 running motion and relative air velocity. Regional $\mathrm{T}_{\mathrm{sk}}$ was the result of the concomitant contribution of 14 these internal and external phenomenons.

(4) In terms of perceptual responses, regional thermal sensations were similar between males and

16 females despite the lower absolute $\mathrm{T}_{\mathrm{sk}}$ for females. In the context of our study, rate of changes in $\overline{T_{s k}}$,

17 regional $\mathrm{T}_{\mathrm{sk}}$ and $\mathrm{T}_{\mathrm{re}}$ were similar between sexes and may partly explain this perceptual outcome 18 (Zhang et al., 2010). Interestingly, mapping perceptual responses revealed that regional sensations across the body were associated with their corresponding absolute regional $\mathrm{T}_{\mathrm{sk}}$ during exercise only, though the relation was different for each sex. To our knowledge, no other studies have explored this

21 spatial feature.

22 The above findings have been obtained from a population of physically active males and females with 23 a relatively narrow range of body fat within each group. Our body-mapping method offers novel 24 insights in the exploration of sex-differences but it can also be valuable in the spatial comparisons of 25 various interventions or populations on one occasion or longitudinally.

\section{Conclusions}


1 A body-mapping approach was able to discriminate spatial thermoregulatory and perceptual responses.

2 In the context of running in the cold, females exhibited lower $\mathrm{T}_{\mathrm{sk}}$ compared to males. However, the

3 relative distribution of regional $\mathrm{T}_{\mathrm{sk}}$ was similar between sexes as highlighted by our population-

4 averaged relative body maps. The regional $\mathrm{T}_{\mathrm{sk}}$ distribution was not explained by the regional

5 variations in skinfold thickness, except within the anterior torso. A dynamic interplay between

6 regional heat production, heat transfer to the surface and heat loss influences regional $\mathrm{T}_{\mathrm{sk}}$ and some

7 determinants have been discussed especially the vasomotor adjustments induced by exercise.

8 Moreover, males and females had similar overall and regional thermal sensations despite the lower $\mathrm{T}_{\mathrm{sk}}$

9 in the females. Unlike fat thickness, these regional sensations proved to be associated with the regional

$10 \mathrm{~T}_{\mathrm{sk}}$ during exercise, but not rest. The present body-mapping data can be useful to increase the

11 resolution of multi-nodal temperature regulation models and it can have practical implications for the 12 design of sport or cold protective clothing.

\section{Role of funding body}

The research presented was co-funded by Oxylane Research (Decathlon R\&D Department) and the Loughborough Design School (Environmental Ergonomics Research Centre) from Loughborough University. Bernard Redortier and Thomas Voelcker (Oxylane Research) contributed to the experiment design and the paper write-up.

\section{Acknowledgments}

The authors would like to acknowledge the support of Dr Simon Hodder and Mr John Pilkington within the laboratory as well as the advice given by Dr David Kerr (Loughborough University) and Dr Ricardo Vardasca (Glamorgan University) regarding infrared image processing. Oxylane Research is acknowledged for co-funding the research.

\section{References}

Borg, G.A., 1970. Perceived exertion as an indicator of somatic stress. Scand J Rehabil Med. 2, 92-98. 
1 Candas, V., 2005. To be or not be comfortable: basis and prediction, Chapter 4, in Environmental

2 Ergonomics, Elsevier Ltd., Oxford.

3 Choi, J.K., Miki, K., Sagawa, S., 1997. Evaluation of mean skin temperature formulas by infrared

4 thermography. Int J Biometeorol. 41(2), 68-75.

5 Clark, R.P., Edholm, O.G., 1985. Man and his thermal environment, Edward Arnold, London.

6 Clark, R.P., Mullan, B.J., Pugh, L.G., 1977. Skin temperature during running-a study using infra-red

7 colour thermography. J Physiol. 267(1), 53-62.

8 Crandall, C.G., Johnson, J.M., Kosiba, W.A., Kellogg, Jr, K.L., 1996. Baroreceptor control of the

9 cutaneous active vasodilator system. J Appl Physiol. 81, 2192-2198.

10 Fiala, D., Havenith, G., Bröde, P., Kampmann, B., Jendritzky, G., 2012. UTCI-Fiala multi-node model

11 of human heat transfer and temperature regulation. Int J Biometeorol. 56(3), 429-441.

12 Frim, J., Livingstone, S.D., Reed, L.D., Nolan, R.W., Limmer, R.E, 1990. Body composition and skin 13 temperature variation. J Appl Physiol. 68(2), 540-543.

14 Gagge, A.P., Stolwijk, J.A., Saltin, B., 1969. Comfort and thermal sensations and associated

15 physiological responses during exercise at various ambient temperatures. Environmental Research.

$162(3), 209-229$.

17 Graham, T.E., 1988. Thermal, metabolic, and cardiovascular changes in men and women during cold 18 stress. Med Sci Sports Exerc. 20(5), S185-192.

19 Havenith, G., Fogarty, A., Bartlett, R., Smith, C.J., Ventenat, V., 2008. Male and female upper body 20 sweat distribution during running measured with technical absorbents. Eur J Appl Physiol. 104(2), $21 \quad 245-255$.

22 Hayward, V.H., Wagner, D.R., 2004. Applied Body Composition, second ed., Human Kinetics, Leeds. 23 Hensel, H., 1973. Neural processes in thermoregulation. Physiol Rev. 53(4), 948-1017.

24 Hunold, S., Mietzsch, E., Werner, J., 1992. Thermographic studies on patterns of skin temperature 25 after exercise. Eur J Appl Physiol Occup Physiol. 65(6), 550-554.

26 Iemitsu, M., Itoh, M., Fujimoto, T., 2000. Whole-body energy mapping under physical exercise using 27 positron emission tomography. Med Sci Sports Exerc. 32(12), 2067-2070.

28 Johnson, J.M., 1992. Exercise and the cutaneous circulation. Exerc Sport Sci Rev. 20, 59-97. 
1 LeBlanc, J., 1954. Subcutaneous fat and skin temperature. Can J Biochem Physiol. 32(4), 354-358.

2 Mack, G.W., Cordero, D., Peters, J., 2001. Baroreceptor modulation of active cutaneous vasodilation

3 during dynamic exercise in humans. J Appl Physiol. 90, 1464-1473.

4 Merla, A., Mattei, P.A., Di Donato, L., Romani, G.L., 2010. Thermal imaging of cutaneous

5 temperature modifications in runners during graded exercise. Ann Biomed Eng. 38(1), 158-163.

6 Mueller, W.H., Joos, S.K., 1985. Android (centralized) obesity and somatotypes in men: association 7 with mesomorphy. Ann Hum Biol. 12(4), 377-381.

8 Ouzzahra, Y., Havenith, G., Redortier, B., 2012. Regional distribution of thermal sensitivity to cold at 9 rest and during mild exercise in males. J Therm Biol. 37(7), 517-523.

10 Park, D., Hwang, J., Jang, K., 1997. Mapping of the human body skin with laser doppler flowmetry. 11 Ann Plast Surg. 39(6), 597-602.

12 Pellerin, N., Deschuyteneer, A., Candas, V., 2004. Local thermal unpleasantness and discomfort 13 prediction in the vicinity of thermoneutrality. Eur J Appl Physiol. 92, 717-720

14 Smith, C.J., Havenith, G., 2012. Body mapping of sweating patterns in athletes : a sex comparison.

15 Med Sci Sports Exerc. 44(12), 2350-2361.

16 Steketee, J., 1973. Spectral emissivity of skin and pericardium. Phys Med Biol. 18(5), 686-694.

17 Veicsteinas, A., Ferretti, G., Rennie, D.W., 1982. Superficial shell insulation in resting and exercising 18 men in cold water. J Appl Physiol. 52(6), 1557-1564.

19 Wagner, J.A., Horvath, S.M., 1985. Influences of age and gender on human thermoregulatory 20 responses to cold exposures. J Appl Physiol. 58(1), 180-186.

21 Walsh, C.A., Graham, T.E., 1986. Male-female responses in various body temperatures during and 22 following exercise in cold air. Aviat Space Environ Med. 57(10), 966-973.

23 Werner, J., Reents, T., 1980. A contribution to the topography of temperature regulation in man. Eur J 24 Appl Physiol. 45, 87-94.

25 Whaley, M.H., Brubaker, P.H., Otto, R.M., Armstrong, L.E., 2009. ACSM's guidelines for exercise 26 testing and prescription, sixth ed., Lippincott Williams \& Wilkins, Philadelphia. 
1 Zhang, H., Arens, E., Huizenga, C., Han, T., 2010. Thermal sensation and comfort models for non-

2 uniform and transient environments: Part I: Local sensation of individual body parts. Build Env.

$3 \quad 45(2): 380-388$.

$4 \quad$ Legends

5 Table 1. Body-mapping of 24 regional skinfold thicknesses (group average, range) across the whole-

6 body for males $(n=9)$ and females $(n=9)$

8 Figure 1. Group averaged body maps of absolute (left panel) and relative (right panel) skin

9 temperature after 40 minutes of running at $70 \% \dot{V} O_{2 \max }$ in a $10^{\circ} \mathrm{C}$ environment for males $(\overbrace{}^{\Uparrow})(\mathrm{n}=9)$ and 10 females ( $(+)(n=9)$ after morphing individual images of the participants in each group onto a reference

11 body shape. Relative maps are obtained by dividing the absolute body map by the group $\overline{T_{s k}}$ at this

12 specific stage. A value of 1 therefore corresponds to the group $\overline{T_{s k}}$

14 Figure 2. Analysis of regional data distribution across the body. Each data point represents the group 15 average for a single body region. Regional skin temperature $\left({ }^{\circ} \mathrm{C}\right)$ in relation to regional skinfold 16 thickness (mm) 5 minutes after entering the $10^{\circ} \mathrm{C}$ environment (A) and after 40 minutes of running at $1770 \% \dot{V} O_{2 \max }$ in the $10^{\circ} \mathrm{C}$ environment (B). Regional thermal sensation votes in relation to regional skin 18 temperature $\left({ }^{\circ} \mathrm{C}\right)$ at rest $(\mathrm{C})$ and at the end of exercise (D) . *significant at $\mathrm{p}<0.05$ 


\begin{tabular}{|c|c|c|c|c|c|c|c|c|c|}
\hline & \multicolumn{2}{|c|}{ FEMALES } & \multicolumn{2}{|c|}{ MALES } & \multirow[b]{2}{*}{ Regions } & \multicolumn{2}{|c|}{ FEMALES } & \multicolumn{2}{|c|}{ MALES } \\
\hline Regions & $\begin{array}{c}\text { skinfold } \\
\text { thickness } \\
(\mathrm{mm})\end{array}$ & range & $\begin{array}{c}\text { skinfold } \\
\text { thickness } \\
(\mathrm{mm})\end{array}$ & range & & $\begin{array}{c}\text { skinfold } \\
\text { thickness } \\
(\mathrm{mm})\end{array}$ & range & $\begin{array}{c}\text { skinfold } \\
\text { thickness } \\
(\mathrm{mm})\end{array}$ & range \\
\hline anterior forearm & 7.3 & $(4.6-9.8)$ & $5.4^{*}$ & $(4.3-7.6)$ & thigh & 24.3 & $(15.5-39.1)$ & $12.9^{* \star}$ & $(9.5-22.1)$ \\
\hline biceps & 6.9 & $(4.3-9.1)$ & $4.9^{*}$ & $(2.5-7.1)$ & suprapatellar & 7.2 & $(4.5-11.3)$ & 6.2 & $(5.0-8.2)$ \\
\hline shoulder & 7.8 & $(4.5-9.9)$ & $6.6^{*}$ & $(4.6-9.0)$ & calf & 12.1 & (8.9-15.2) & 10.0 & $(4.5-16.9)$ \\
\hline clavicular & 7.6 & $(5.3-10.1)$ & $4.9^{* *}$ & $(4.0-6.2)$ & posterior forearm & 6.2 & $(4.3-8.7)$ & $4.5^{\star \star}$ & $(3.6-5.6)$ \\
\hline pectoral & 8.6 & $(5.7-11.7)$ & 7.7 & $(4.9-10.2)$ & triceps & 16.6 & $(10.8-22.9)$ & $7.5^{\star \star}$ & $(5.3-11.1)$ \\
\hline chest & 11.8 & $(9.3-14.9)$ & $6.1^{* *}$ & $(4.5-7.4)$ & neck & 14.3 & $(11.5-17.5)$ & $9.9^{* *}$ & $(8.1-12.5)$ \\
\hline nipple & 8.7 & $(6.7-10.6)$ & 8.5 & $(6.0-11.2)$ & suprascapular & 10.5 & $(7.9-13.3)$ & 9.9 & $(7.6-13.9)$ \\
\hline midaxillary & 10.8 & $(7.5-14.2)$ & $7.7^{\star *}$ & $(6.1-9.1)$ & scapular & 11.6 & $(7.8-13.9)$ & 11.5 & $(8.4-16.5)$ \\
\hline upper abdominal & 13.1 & $(8.1-19.4)$ & 13.6 & $(9.0-27.3)$ & subscapular & 12.6 & $(8.2-17.8)$ & $10.0^{*}$ & $(8.2-12.3)$ \\
\hline external oblique & 11.9 & $(7.7-18.5)$ & 10.0 & $(7.5-21.0)$ & infrascapular & 12.9 & $(8.1-18.3)$ & 10.6 & $(8.7-13.1)$ \\
\hline suprailiac & 18.7 & $(13.1-25.3)$ & $13.7^{\star}$ & $(7.7-25.9)$ & lumbar & 19.7 & $(9.9-30.9)$ & $13.6^{*}$ & $(9.0-24.3)$ \\
\hline abdominal & 13.7 & $(12.2-14.9)$ & 14.8 & $(11.4-23.3)$ & lumbosacral & 18.6 & $(9.1-27.5)$ & $11.1^{\text {** }}$ & $(7.6-16.2)$ \\
\hline $\begin{array}{l}\text { sum of } 24 \\
\text { skinfolds }\end{array}$ & 293 & $(224-362)$ & $222^{* *}$ & $(177-324)$ & & & & & \\
\hline
\end{tabular}

* significantly different from females at $\mathrm{p}<0.05$; ** significantly different from females at $\mathrm{p}<0.01$ 



\section{Highlights}

2 - Females exhibited lower $\overline{T_{s k}}$ and regional $\mathrm{T}_{\mathrm{sk}}$ than males

3

- $\mathrm{T}_{\mathrm{sk}}$ distribution pattern was similar between males and females

4

- $\mathrm{T}_{\mathrm{sk}}$ distribution was not associated with the distribution of skinfold thickness, except for the

5 anterior torso

6

- Thermal sensation distribution was associated with $\mathrm{T}_{\mathrm{sk}}$ distribution during exercise 